\title{
The Rights Discourse and the Obligation of STATES to ADMit IMMigRANTS
}

\section{Chaim Gans*}

I argue in this Article that states have two types of moral duties with regard to their intake of immigrants. First, they have a duty to accept quotas of immigrants who have no individual rights to entrance prior to the determination of specific immigration criteria applicable in their case. Second, they have a duty to admit immigrants who are entitled to enter as individuals, namely, refugees and immigrants, who wish to enter the state for family reunification. However, under certain conditions, states could be justified in limiting the entrance of refugees and family reunification immigrants, who might eventually be eligible for naturalization by means of various qualifications and even quotas.

Initially, I defend the complex thesis stated above by rejecting two positions supported by contemporary liberal immigration theorists. One position advocates a cosmopolitan human right to immigration, namely, every single individual's right to immigrate into any country of his/her choosing. The other position claims that states have a universal right to lock their gates to immigration. Finally, I argue for the middle-ground position stated above.

\section{INTRODUCTION}

I argue in this Article that states have two types of moral duties with regard to their intake of immigrants. First, they have a duty to accept quotas of immigrants who have no individual rights to entrance prior to the determination of specific immigration criteria applicable in their case. Second, they have a duty to admit immigrants who are entitled to enter as individuals, namely, refugees and immigrants, who wish to enter the state for family reunification. However, under certain conditions, states could be justified in limiting the entrance of refugees and family reunification immigrants, who might eventually be eligible for naturalization by means of various qualifications and even quotas.

Initially, I defend the complex thesis stated above by rejecting two positions supported by contemporary liberal immigration theorists. One position advocates a cosmopolitan human right to immigration, namely, every single individual's right to immigrate into any country of his/her choosing. The other position claims that states

\footnotetext{
- Professor of Law, Tel Aviv University.
} 
have a universal right to lock their gates to immigration. Joseph Carens is the main proponent of cosmopolitan immigration rights. He supports this position mainly by invoking the right to free movement. ${ }^{1}$ Other contenders, Mathias Risse and Michael Blake, support it by invoking what they call the "egalitarian ownership of the world argument." At the other end of the spectrum, Christopher Heath Wellman argues for the view that states are entitled to lock their gates. He does this by invoking the right to freedom of association. ${ }^{3}$ In the first part of this Article, I reject the cosmopolitan position with regards to immigration. In the second part, I reject the claim that freedom of association can support states in locking their gates. Finally, I argue for the middle-ground position stated above.

\section{Universal Immigration Rights of all Individuals to all Places}

\section{A. Joseph Carens' Freedom-OF-Movement ARgument}

Carens argues that every individual has the right to immigrate into any country by invoking the social and economic interests that justify freedom of movement. Since the importance of this freedom is presupposed by the practices espoused by liberalism, and since its justification stems from people's social and economic interests, rather than from political interests, Carens wonders why political borders should define the scope of freedom of movement. ${ }^{4}$ Some writers (David Miller, John Rawls) ${ }^{5}$ have pointed out that the scope of freedom of movement necessary for the fulfillment of economic and social interests need not be unlimited; rather, it should only be reasonable. Carens responds that if this were the case, then large countries, such as Canada, could have prohibited their citizens' freedom of movement throughout the country and limited it to confined areas. Nevertheless, most countries, including large countries, allow their citizens to move within their entire territories. From this he infers that limiting

\footnotetext{
'I refer here to Carens' arguments as presented in some final drafts of chapters 9 "The Case for Open Borders" and 10 "The Claims of Community" of his forthcoming book that he kindly allowed me to read in 2009; see JOSEPH CARENS, The ETHICS OF IMMIGRATION (OUP, forthcoming).

${ }^{2}$ Michael Blake \& Matthias Risse, Is There a Human Right to Free Movement? Immigration and Original Ownership of the Earth, 23 Notre Dame J.L. Ethics \& Pub. Pol'y 133, 138 (2009).

${ }^{3}$ Christopher Heath Wellman, Immigration and Freedom of Association, 119 ETHICs 109 (2008).

${ }^{4}$ CARENS, supra note 1 , at ch. 9.

${ }^{5}$ John Rawls, A TheORY OF Justice 213 (1971); David Miller, Immigration: The Case for Limits, in Contemporary Debates in Applied Ethics 193 (Andrew I. Cohen \& Christopher Wellman eds., 2005).
} 
people's freedom of movement to only the territories of their states is arbitrary. He believes that people should be allowed to move around and settle freely anywhere in the world. ${ }^{6}$

This is too hasty a conclusion. The claim that people have social and economic interests in a reasonable but not necessarily unlimited scope for their freedom of movement, together with the claim that-in the case of very large states-this scope need not overlap with the entire territory of such states, does not entail that limiting freedom of movement to the territory of people's states is arbitrary. Nor does it entail that the scope of freedom of movement must be cosmopolitan. Firstly, it could be the case that large states do not limit their citizens' freedom of movement to confined areas within their entire territories simply because they do not have good reasons for doing so (whereas, as we shall see later and, as Carens himself acknowledges, there are very good reasons for states to limit the number of foreigners moving into their territories). Secondly, given the danger that governments will abuse their authority and confine their citizens' movement, political morality should not allow the existence of such authority. Thirdly, a state is meant to be a home for its citizens. Limiting their access to certain confined areas of the state means that only these parts can be their home, which diminishes the concept of nationhood in the broad sense of the term. If there are no good reasons for enacting such limitations, why enact them? There can sometimes be justifications for limiting citizens' movement within states, as in the case of the limited access of non-native North Americans to native reservations. And sometimes, there are good reasons to do the opposite, namely, allow people freedom of movement to settle in areas nearby and outside their states, as in the case of miniature states such as Monaco, Andorra, and Liechtenstein. ${ }^{7}$ In any event, it seems that neither the claim that in some cases it is appropriate to extend the scope of freedom of movement beyond one's state territory, nor the arguments for why people should be allowed to move freely within their states even if their states are larger than is reasonably required to satisfy their economic and social interests, are claims which

\footnotetext{
${ }^{6}$ CARENS, supra note 1 , at ch 9.

${ }^{7}$ Nationals of Andorra and Monaco do not require a work permit in order to work in France (see Antonella C. Attardo, France, International Co-Operation on Migration, available at http://www.legislationline.org/topics/topic/10/subtopic/43/country/30 (last visited Mar. 16, 2010)). An agreement signed between San Marino and Italy on 1971 allows the nationals of both Republics to exercise any profession or function in the other Republic under the same conditions as the Republic's nationals (Jorri DuUrosma, Fragmentation and the International Relations of Micro-States 224 (1996). A treaty concluded on 1964 allowed Liechtenstein and Swiss nationals to receive a residence permit and work permit in the other country upon request (id. at 167). Since 1995, Liechtenstein nationals may work and settle in the EEA member states.
} 
entail that people by their very nature have basic interests in cosmopolitan freedom of movement.

Moreover, even if people had such interests, it is doubtful whether these interests could establish a right to cosmopolitan free movement. As Carens himself admits, having an interest to do $\mathrm{A}$ is not equivalent to having a right to do $\mathrm{A}$. In order for $\mathrm{X}$ 's interest to do A to justify X's right to do A, the interest in question must also justify imposing duties on others at least to refrain from interfering with $X$ 's attempt to do A. In order for X's interest to justify the imposition of such duties on others, $X$ 's interest must be considered to be so important that, as a matter of principle, it overrides or excludes common interests those others might have in preventing $\mathrm{X}$ from doing A. ${ }^{8}$ Carens himself lists several types of reasons why states might be justified in preventing the entrance of non-members. These include considerations of public order, national security, the protection of liberal institutions, the protection of welfare systems and the preservation of cultures. ${ }^{9}$ Two characteristics of these considerations are particularly important. Firstly, they comprise diverse issues, which states often need to take into account in making decisions regarding the expected arrival of foreigners, especially if they are expected to arrive in large numbers. Secondly, such considerations could in principle override the interests of potential non-refugee or non-family immigrants in entering a particular state. The question of whether they actually override these interests requires a case-by-case examination and cannot be answered in advance. Carens acknowledges all this. It therefore follows that even if we accept his claim that people's interests in cosmopolitan free movement stem from basic human needs, they nevertheless do not entail rights. These interests do not as a matter of principle override or exclude the interests that states might often have in not admitting immigrants. ${ }^{10}$ In other words, they are not duty-imposing interests, and thus they are not right-producing interests.

\footnotetext{
${ }^{8} \mathrm{I}$ assume here that having a right means having an interest that justifies the imposition of duties on others (Joseph Raz, On the Nature of Rights, 93 Mind 194, 195 (1984). "X has a right if and only if $X$ can have rights, and other things being equal, an aspect of $X$ 's well-being (his interest) is a sufficient reason for holding some other person(s) to be under duty.") and that duties are act-types justified by reasons which relative to act-tokens falling under this act-type enjoy a principled hierarchical priority over some types of other reasons and interests likely to collide with the reason justifying the performance of act-tokens falling under the duty-act-type. See Chaim Gans, The Concept of Duty (1981) (Ph.D. dissertation, Oxford University) (on file with the author). I also should mention that I conduct most of my argument in this Article within the framework of interest theories of rights, particularly Raz's.

${ }^{9}$ CARENS, supra note 1 , at ch. 10.

${ }^{10}$ For example, a common reason why people may not wish to pay income tax is their interest in keeping as much as possible for themselves. Paying income tax is often referred to as a duty because
} 
Carens tries to avoid this conclusion by observing that considerations of public order and cultural preservation could override the interest in free movement only if there is a threat that great numbers of people would immigrate to a given country. He then argues that the dangers attached to a given right through the possibility that all those in possession of the right will implement it simultaneously are just as valid in the case of freedom of expression, the right to medical care, and the right to walk on urban sidewalks-and yet we do not deny these rights for this reason. ${ }^{11}$ However, there are two important differences between the latter examples and the right to universal immigration. First, it is highly unlikely that all people would simultaneously activate their freedom of expression, or walk on the sidewalk all at the same time, or that frequent large-scale disasters would lead a very great number of people to simultaneously require medical care. In contrast, in our currently non-ideal world there is a high probability that if permitted, masses of immigrants would inundate many states within a short period. Second, it seems that as a matter of principle, the universal interests in medical care and freedom of expression ought to outweigh many other common interests of people on whom the duties correlative to these rights are imposed. For example, as a matter of rule, and with regard to act-tokens belonging to the act-type of paying healthcare tax (namely, particular acts falling in the category of paying healthcare tax) people's interest in healthcare should outweigh people's interest in keeping all of their income to themselves. Keeping all of our money to ourselves is clearly a common interest. Also, it seems desirable that the interests in information and expression should prevail over the interests of individuals in not being emotionally offended by a particular political point of view or artistic expression. However, it is not within public consensus-nor should it be-that the interests of all people in immigrating to any part of the world must, as a rule, offset the interests in public order, in preserving cultures and in the enactment of economic justice in communal settings. In this regard, it seems undesirable to generalize about hierarchies among values and interests. The question of the priorities must be considered on case-by-case bases, as there does not appear to be a clear normative hierarchy. Removed from the actual circumstances under which they clash, it is unclear which interests come first (As I already argued above, general prima facie rights represent principled hierarchies

this desire not to pay taxes should in principle be overridden by the interests justifying the duty to pay income-tax. I believe that most people do not have this attitude towards such matters as the preservation of a state's culture and its public and economic order, which frequently weigh against admitting immigrants.

"Carens, supra note 1, at ch. 10. 
among values and interests likely to clash with each other regularly relative to the right's act-type).

My argument here has so far assumed a conception of rights according to which rights designate act-types justified by certain reasons which, relative to these acttypes, in principle override some types of reasons that frequently militate against performing act-tokens belonging to the right's act-type. I reject the claim that there is a cosmopolitan right to immigrate by pointing out that there are in fact many cases in which reasons militating against admitting immigration deserve to be weighed against the interests of the potential immigrants and could in some cases override them.

The common presence of reasons that could in principle justify the refusal of states to admit immigrants also makes the notion of a purported cosmopolitan right to immigrate unacceptable from the perspective of another major theory of rights, according to which rights are choices or mini-sovereignties of their holders. ${ }^{12} \mathrm{My}$ guess is that Carens would not want to grant the potential immigrants themselves the power to balance between the reasons supporting their purported right to immigrate and the reasons that could justify the refusal of states to admit them. He would probably think that this power should be granted to the admitting state or to an international authority. The fact that this power would not be held by the potential immigrants themselves thwarts the possibility of viewing their interest to immigrate as a possible basis for an individual right to immigrate that they themselves hold. ${ }^{13}$

\section{B. Blake and Risse's Egalitarian OWNership of the World Argument}

Michael Blake and Mathias Risse argue for universal immigration rights by claiming that in principle each of us has territorial and resource rights within the jurisdictions of ail states. They argue that all people have such rights because such resources "are necessary for any human activities to unfold" and because "such resources have come into existence without human interference."14

${ }^{12}$ H.L.A. Hart, Legal Rights, in H.L.A HaRT, EsSaYs on Bentham 162, 183 (1982); see also H.L.A. Hart, Are There Any Natural Rights, 64 Phil. Rev. 175 (1955).

${ }^{13}$ Consider Israel's right of return for Jews. This right does not allow the state or anybody else discretion to refuse any Jews entrance (unless a potential returnee fits into one of the exceptions to the law). It is up to individual Jews to decide whether or not they wish to enter Israel. Would Carens want to allow all individuals in the world to be those who weigh the considerations for and against their entrance into a country and to be those who make the decision regarding their entrance?

${ }^{14}$ Blake \& Risse, supra note 2, at 137. 
They suggest distinguishing among the different assets within the jurisdiction of various states, between those that could be considered "raw resources," which came into being without human interference, and which are within the joint possession of all humanity, and those in which specific people or groups of people have invested labor. As such, the latter are no longer within the public domain. Blake and Risse argue for appraising the value of territories according not only by their sizes, but also by the resources they contain, their bio-physical and geographical characteristics, and the value of all these components to various human needs and interests. If the resultant appraisal of a certain state territory divided by its number of residents is larger than the value of all global territories divided by total number of humans, then that state's territory is considered to be under-used, and the state should be compelled to enable immigrants to settle it. ${ }^{15}$

Blake and Risse's underlying thesis - that of humanity's egalitarian ownership of the earth-is one I concur with. ${ }^{16}$ However, it seems to me that they make too rapid a move from this thesis to conclusions regarding the specific right of people to immigrate into particular states and the obligation of these states to receive such immigrants. The first and perhaps most obvious point that weakens Blake and Risse's transition from humanity's egalitarian ownership of the earth to acknowledging potential immigration rights for individuals is that immigrants enter states in order to establish their lives there. In order to do this, they would need to appropriate resources that-according to Blake and Risse-belong to humanity as a whole. Why should states not be allowed then to offer to buy out the potential immigrants' share of raw resources located within their jurisdictions, instead of granting these potential immigrants entrance? Another rather obvious point is that immigration does not merely mean moving from one geographical site to another, or appropriating or using a state's material resources; immigrants also enter the state's social, cultural and political spheres. These social, cultural and political spheres are usually interlocked with important parts of the state's material resources, mainly the state's territory. It would seem, therefore, that even if one concedes to Blake and Risse's claim that part of these resources and territories are owned by humanity as a whole, states could offer to shrink their territories, leaving "enough and as good" for potential immigrants, without admitting them into the state's social, cultural and political spheres. Surely a state's social, cultural, and political

${ }^{15} I d$. at $150-51$.

${ }^{16} \mathrm{I}$ agree with this thesis and presuppose it in my discussion of the right to national selfdetermination. In fact, such thesis is presupposed by the Zionists' argument for the Jews' return to Palestine. 
resources are the product of the labor and investment of the state's own people, and therefore do not belong to humanity as a whole; in any case, at least not due to the rationale that Blake and Risse invoke in order to claim that some material resources within states belong to humanity as a whole. It seems, therefore, that even granting Blake and Risse's argument, from the point of view of a state expecting entry petitions by potential immigrants, a possible legitimate response would be to offer potential immigrants material alternatives without allowing them to become a significant part of the state's society, culture, and politics.

The points I have just made concern possible responses that states could address to potential immigrants knocking on their gates in order to obtain their share in humanity's egalitarian ownership of the earth. These responses do not dispute the egalitarian ownership thesis; they merely refuse to interpret it as necessarily implying immigration rights. However, the claimant individuals who share the egalitarian ownership of the earth with the rest of humanity might also reject this interpretation. Consider the Zionist immigration to Palestine. In Blake and Risse's terms, from its inception Zionism claimed that the territory of Palestine was in a state of underuse, as conveyed by the following rather objectionable quote: "A land without a people for a people without a land." 17 But the above claim also had much less troubling versions that invoked Palestine's low population density. At the time, the Zionist immigration to the Land of Israel was the immigration of a national group intending to establish self-determination for the Jews, rather than that of individuals aiming to integrate themselves into the culture and nation currently living in the Land of Israel. In other words, in the name of the egalitarian ownership thesis, the Zionist movement made claims that were more ambitious than the demands individuals might make in entering states. In the context in which they were made, I believe these demands to have been just. If this is indeed the case, then the move from the egalitarian ownership thesis to immigration rights that individuals hold vis-à-vis states under-using their resources ignores many other possible rights that could be claimed by virtue of the egalitarian ownership thesis. The rights in question could be immigration rights to integrate into the state's society, rights to settle in its territory in order to privately own material resources without integrating into the state's community, rights to immigrate and in addition change the cultural and political nature of the state in question or reduce its

${ }^{17}$ The phrase "Palestine is a country without people; the Jews are a people without a country" was used by Israel Zangwill (Israel Zangwill, The Return to Palestine, 2 New Liberal Rev. 615 (1901)) though it was first formulated by Lord Shaftesbury in 1851 . 
territory in order to establish a new state, or rights to exchange the above rights with other commodities, or different combinations of some of the above alternatives.

The answer to the question of which of the above alternatives is appropriate in a specific context requires a broader theory, in which the egalitarian ownership thesis comprises just one component. Such a theory would necessarily include answers to questions concerning the limits of freedom of association, and the nature and limits of national and cultural rights. Only a comprehensive analysis of all the components of this theory can inform us as to which immigration rights could be derived from the egalitarian ownership thesis.

Moreover, we must remember that this complex theory would be just one component of an ideal theory of global justice. In our imperfect world, such a theory is inapplicable because there are no institutions sufficiently developed to secure its coordinated enforcement on all its subjects, namely, all the states under-using their resources. States that would be required to act according to this theory would argue that other states have similar characteristics and should be likewise obligated. Without securing the coordinated action of other relevant states, it would therefore be unjust to require them to be the only ones to abide by the theory.

In sum, the egalitarian ownership thesis is only justified within a global theory of justice for an ideal world. It cannot be a part of a non-ideal theory. And within an ideal theory, the possible duties and rights it gives rise to with regard to immigration are manifold. In some cases, they are duties to admit individual immigrants, while in other cases these duties include allowing collective immigration. In yet other cases, the duties should be to evacuate territory and resources in order to allow individuals or a collective to settle in these territories. And occasionally, states should be allowed to buy off the required territories and resources from those demanding them.

\section{Freedom Not to Associate and the Right of States to Lock THEIR GATES}

So far I have rejected the arguments purporting to establish cosmopolitan immigration rights on the basis of freedom of movement and the principle of egalitarian ownership of humanity over the earth. I now reject an attempt made by Christopher $\mathrm{H}$. Wellman to deny any immigration rights whatsoever. ${ }^{18} \mathrm{He}$ argues that the right to freedom of association, which is also the freedom not to associate, implies that states have

\footnotetext{
${ }^{18}$ Wellman, supra note 3.
} 
the right to lock their gates to potential immigrants. ${ }^{19}$ The right of states to turn immigrants away stems not only from such tasks as maintaining public order and national security or protecting their economic and cultural integrity. States have the right not to admit immigrants without the need to justify this. According to Wellman, this right is comparable to the right individuals have not to marry just anyone who happens to have proposed marriage to them. As for the counter-argument that the effects of forced marriage on an individual are much harsher than the outcome of forcing a state to accept immigrants, Wellman responds that it is not the importance of the interest justifying the right to associate and dissociate that justifies a state's right to lock its gates, but rather, the very right to associate or dissociate in and of itself. For example, he argues that people's interest in forming golf clubs is not a fundamental one, but once they have formed such organizations, they are entitled under freedom of association to lock their clubs to others without having to justify their refusal to admit new members. And if such exclusion is allowed for golf clubs, clearly states should also be entitled to it, as people's interests in their states are much more significant than those held by golf club members in their clubs.

My response to Wellman's claims above is based on one of the arguments I made against Carens' attempt to justify a universal right to immigration. While rights are not dependent on the absolute importance of the interest or interests underlying them, they are dependent on the relative importance of these interests vis-à-vis prevalent interests of others that might be harmed if obligated to serve the interests justifying the given right. Since only relatively insignificant interests of others might be harmed if we recognize the freedom of the members of a golf club not to associate with others who want to join their club, there is no harm in recognizing this right even though the interest in playing golf with select partners is not a particularly critical one. One might say the same for the right to scratch oneself when nothing itches; we certainly lack an important interest in scratching ourselves under such conditions. However, we still have the right to do so, since it is unlikely that recognizing the duties imposed on others in order to protect this right will harm significant interests of those others.

Recognizing the right of states to control immigration to the point of a complete lock-down of their gates would not be a similar case. Wellman correctly notes that the interest that could justify states in such a move is the same interest that communities of citizens have in shaping their identities and controlling their own development. ${ }^{20}$

\footnotetext{
${ }^{19} \mathrm{Id}$. at $109-10$.
}

${ }^{20} \mathrm{Id}$. at $117-19$. 
However, this interest could be protected not only through a full blockage of immigration, but also by establishing specific immigrant quotas and making specific demands on potential immigrants regarding their integration in the state admitting them. Moreover, this interest (unlike the interest that members of a golf club have in shaping their club) is likely to conflict with frequent interests that people elsewhere in the world have in territories and resources that, according to some writers, belong to all of humanity (see the previous section of this Article). People's interests in shaping their identities and other interests in self-determination also conflict with the diverse interests that large groups of people all over the world might have in leaving their states. Allowing states to control immigration into their territories necessarily also grants them control over the interests of all those other people; allowing them to lock their gates means allowing them to ignore these interests and to render other individuals' rights to exit their states devoid of any practical significance.

In order to satisfy citizens' interest in determining the future identity of their state and preventing immigration from hindering this identity, it is possible to establish an international authority whose task would be to control immigration and allocate it to different countries according to the requirements of global distributive justice. This potential justice also requires the distribution of the risks that immigration creates to the identities of different states, which could be reduced by demanding that potential immigrants commit themselves to integrating into the culture of their target country if they are allowed in. I am not arguing that such a global authority should really be established; only that it is an alternative method for satisfying the interest that according to Wellman justifies states' right to control immigration.

Moreover, even if the appropriate method for satisfying the interests that citizens might have in preserving the identity of their country should be to acknowledge their country's right to control immigration, it seems that the interests that such a right could damage create strong reasons for acknowledging many limitations on it. Perhaps the right ought to be a disjunctive right, namely, a right of states to choose between either shrinking their territories while locking their gates to immigration, or controlling immigration that presupposes their duty to admit certain quotas of immigrants on whom duties to integrate in some way are imposed.

Wellman is aware of the price that potential immigrants would have to bear if states are acknowledged as having a right to control immigration or lock their gates. $\mathrm{He}$ is aware of the existence of wretchedly poor and politically persecuted people around the world, and he acknowledges the fact that states have obligations toward these people. However, he argues that such obligations need not affect the right of states to lock their gates in the name of their freedom to dissociate. Their obligations 
toward the wretchedly poor and the persecuted people of our world could be fulfilled by assisting them in their own countries, either economically or politically. At most, he argues, we should acknowledge disjunctive duties that states have toward potential immigrants-either to admit them or to assist them in their own states. ${ }^{21}$

In meeting the interests of potential immigrants belonging to these groups, there are surely circumstances in which the disjunctive duties he mentions could be sufficient. However, three observations must be made in this regard. Firstly, on occasion it is impossible to assist the wretchedly poor or the politically persecuted in their own country. Admitting them into the country on whose gates they are knocking is usually the only way to assist them. Secondly, potential immigrants consist not only of the wretchedly poor and the politically persecuted. The case for the purported rights of states to lock their gates must also be balanced against the universal right people should have to emigrate from their countries. In order for this right not to be devoid of any meaning, states around the world cannot be allowed to refuse admission to all immigrants. If the right to emigrate is to be of some practical significance, states that are able to do so must assume an obligation to take in at least some quotas of immigrants. Thirdly, as mentioned earlier, in order to allow citizens to influence the identity of their states and to shape it, it is enough to impose limitations on the number of immigrants and to require that those who are allowed in integrate into the society of the target state. It is not necessary to allow them to keep out all immigrants. If the citizens of a state that is otherwise able to admit immigrants refuse to admit them for cultural reasons, then perhaps such a state should be allowed to lock its gates, but only on the condition that it shrinks territorially. ${ }^{22}$

Having rejected the desirability of recognizing a universal right of all states to lock their gates and also the desirability of recognizing a right of all individuals to immigrate anywhere they choose, I now argue for two types of obligations that states should assume regarding immigration. Firstly, on a case-by-case basis, they must periodically admit quotas of immigrants who do not possess individual rights to immigrate prior to the formation of such quotas and their inclusion in these quotas. I argue that the obligation in question is a perfect obligation of justice and not an imperfect obligation of charity-at least from the perspective of an ideal theory of global justice. Secondly, states must assume an obligation to admit refugees and

\footnotetext{
${ }^{21}$ Id. at $128-29$.

${ }^{22}$ Walzer suggests this when talking about the policy known as "White Australia." MicHAEL WALZER, SPHerES OF Justice 46-48 (1983).
} 
immigrants seeking reunification with their families. While this obligation could be qualified under exceptional circumstances, it is an obligation benefiting specific individuals who already have rights to enter a state prior to that state's obligation to admit them. It thus clearly belongs to the realm of "justice" rather than "charity," even within non-ideal theory.

\section{PARTIAL IMMigration Rights}

\section{A. The Obligation of States to Admit Immigrants in Quotas}

Despite my previous rejection of Carens' claim that each individual worldwide has a fundamental social and economic interest in moving all over the world, justifying a universal right of all people to enter any state, it still seems to me that large numbers of people worldwide have circumstantial yet important interests in leaving their states. Moreover, just as democracy and human rights necessitate that states do not possess a power to limit their citizens' freedom of movement within their territories, it is critical that they do not have the power to limit their citizens' right of exit. The importance of the right to emigrate is widely acknowledged. In order to enable compliance with the circumstantial yet important interests of many people worldwide in emigrating from their countries-and to make the political right of exit meaningful-states must acknowledge an obligation to periodically admit at least a limited numbers of immigrants.

Some would claim that since many countries have self-interested reasons to take in immigrants anyway, recognizing a moral obligation to do so is redundant. Moreover, the right to marriage does not become meaningless despite the fact that there is no correlative duty to get married; likewise for the right of exit from states. Many people wish to get married regardless of the fact that they do not have an obligation to do so. In the same way, many countries seek to admit immigrants without being required to do so. ${ }^{23}$

\footnotetext{
${ }^{23}$ David Miller makes this argument (Miller, supra note 5, at 197), which Wellman invokes: Obviously if no state were ever to grant entry rights to people who were not already its citizens, the right of exit would have no value. But suppose that states are generally willing to consider entry applications from people who might want to migrate, and that most people would get offers from at least one such state: then the position as far as the right of exit goes is pretty much the same as with the right to marry, where by no means everyone is able towed the partner they would ideally like to have, but most have the opportunity to marry someone.
}

Wellman, supra note 3, at 136. 
The above analogy is only partially justified. Firstly, the desire to get married even in absence of an obligation to do so is widespread enough to make the chances that most people would get married very high indeed. However, the independent interest some states have in admitting immigrants is not as widespread. Moreover, reliance on the contingent interests that some states might have in accepting immigrants, leaves people's right of exit dependent on the good graces of a particular state's current interests. It might also result in an unequal division of the burden that states must bear in meeting this global need.

The dependence of emigrants on the good graces of particular states, and the unequal division of the burden posed by immigration, could have been considered inevitable if it weren't for the fact that marriage and immigration differ from one another in an additional normatively significant aspect. Even if most people did not wish to get married, the obvious reasons against forcing marriage upon people are clearly more powerfui than the reasons for allowing forced marriage. The same does not seem to hold with regard to obliging states to set immigrant quotas, at least so long as these quotas are properly regulated. There is no reason not to require states today to set adequately-monitored immigrant quotas. Under such a model, immigration may not result in any harm to states, and if it does, the damage (given the regulation hypothesis) would be minor relative to the benefits to the important cause served.

The obligation of states to admit immigrant quotas is a duty stemming from an ideal theory of justice. Justice requires coordinated action on the part of all or most of its subjects. If such coordinated action is impossible, it would be unjust to expect some of the relevant actors to comply with the rules of justice without the promise that others would act likewise. Therefore, in our non-ideal world, in which no authority can ensure that all or most states would fulfill their duties and set immigrant quotas, it must be left to each state to decide whether or not to comply with the duty to admit immigrants. This duty is therefore similar to the imperfect duty of charity. Immigrants entering on these quotas cannot be conceived as having individual rights to immigrate, just like recipients of charity are not considered to have a right to the charity that they have received.

However, the similarities between the obligation of states to admit quotas of immigrants and the obligation of individuals to give money to charity do not make the peremptory force of the two entirely equivalent. As individuals, we are obliged to give charity after fulfilling our duties of justice to contribute to the welfare of others by paying taxes. There are policy considerations and autonomy-based reasons to preserve the imperfect force of the duty of charity. It would not be charity otherwise. The claim that the duty that states might have to admit immigrant quotas is an imperfect duty 
is justified not because it is important to provide states an opportunity to contribute to humanity as a whole only after they have already been compelled to carry out a range of justice-based strict obligations toward non-members. Rather, it is justified because it is impossible to impose the full range of justice-based obligations on states. Consequently, it seems that states should consider their obligation to admit immigrant quotas as a strict or 'juridical' justice-based duty. It is not the inherent nature of this duty, but only its unenforceability, which makes it similar to duties of charity.

Despite the strictness of this duty, it is a much less burdensome duty than that which would have applied to states if a universal human right to immigration were morally acknowledged. Those who argue for a universal immigration right could claim that the right they are supporting is just a presumptive right that could be overridden by other considerations. Therefore acknowledging cosmopolitan immigration rights would not impose heavier burdens on states than the burdens imposed by acknowledging an obligation to admit periodical quotas of immigrants. It seems to me that this is what Carens meant when he argued that the realization of many human rights depends on the fact that masses of people do not attempt to realize their rights simultaneously. A similar argument could also be made by people believing that states have a right to lock their gates. They could also argue that the right in question is just a prima facie right, and it is therefore possible that other considerations would override it and make it obligatory for states to admit immigrants despite their presumptive right to lock their gates. Wellman, in fact, says just that. ${ }^{24}$

This argument, however, ignores the distinction between the question of whether there is justification for acknowledging a general prima facie right to do something or another, and the question of whether it is justified to consider a given general prima facie right as decisive in one case or another. ${ }^{25}$ The two questions belong to two different levels of practical and moral thinking. Most, if not all, of the general rights we acknowledge are prima facie rights, namely, rights that could be overridden by other rights and even lesser types of considerations. However, not all our legitimate interests can serve as justifications for prima facie rights to do something or another in the service of those interests. As I already explained earlier, in order for a given interest to justify a general prima facie right to commit acts of type A, the interest must be considered one that enjoys a sort of principled normative priority over considerations

\footnotetext{
${ }^{24} \mathrm{Id}$. at $113-14$.

${ }^{25}$ This distinction is analogous to Rawls's distinction between justifying a practice and justifying individual acts falling under it. See John Rawls, Two Concepts of Rules, 64 PHIL. REv. 3 (1955), which mentions even earlier sources for the present distinction.
} 
that are likely to militate against it in the context of performing act-tokens falling under category A. For example, the expressive, informative, and political interests justifying the prima facie right to freedom of expression are considered to enjoy a principled priority over many interests that are likely to militate against freedom of expression. These interests enjoy such priority over economic interest people might have to suppress speech, over interests people have in not being offended by what others say, etc. However, the fact that the interests in free speech enjoy a principled priority over some interests likely to militate against them in the context of speech does not necessitate that these interests enjoy such priority over all the interests that might militate against them. There are some interests that in fact enjoy a principled priority over the interests in free speech. They create a principled exception to the principled priority of free speech. The interest people have in not being libeled is one example. And yet other interests have neither a principled priority over the interests justifying free speech, nor are they automatically inferior to the interests justifying free speech. With regard to the latter interests, one cannot generalize in advance as to whether they take precedence over the interests supporting free speech, or vice-versa; such a determination can only be made by taking into account the particular circumstances in which these two kinds of interests conflict. Interests in state security constitute a case in point. The existence of considerations that could override a right, depending on the relative strength of these considerations in particular circumstances, and those that a priori define the limits of the right, cannot serve as reasons for denying the right itself. Acknowledging the right to free speech is still necessary because there are important considerations which might frequently militate against it, and which, as a matter of principle, are normatively inferior to the interests justifying this right. Regarding the purported cosmopolitan right to immigration, it is difficult to specify interests that could both justify it, and which are in principle normatively prior to states' interests likely to militate against admitting immigrants (i.e., public order, cultural preservation and national security). The answer to the question of whether to admit or deny any particular individual interested in immigrating to a particular country should be decided on a caseby-case basis under the umbrella of periodical quotas that every country should be bound to set. However, two classes of individuals should be regarded as exceptions to this rule: Immigrants seeking family reunification and political or economic refugees.

\section{B. The Obligation of States to Admit Immigrants Seeking Family Reunification AND REFUGEES}

The discourse of individual immigration rights which obviate case-by-case balancing of various other considerations is appropriate with regard to refugees and family 
immigrants, for reasons explained above. The interests of these specific groups in immigration cannot be served other than by admitting them as immigrants. Their interest in immigration should prevail either because states lack significant interests against letting them in, or because such interests should in principle be considered morally inferior to the interests of these potential immigrants in immigrating.

\section{Immigrants SeEking Family Reunification}

The importance of their interests in being reunited with their family requires no proof. If one's family member resides in a different country, there is no way of meeting one's interest in unification with one's kin other than allowing one of the two parties to immigrate to the other's state. Since most people do not need to immigrate in order to fulfill their interest in family unification, it is rather unlikely that providing a right to immigration on this basis will harm other important interests that states have (such as, maintaining public order, economic justice, and preserving cultural their citizen's identity). Therefore, it seems appropriate to assume that family-unification-based immigration does not threaten significant prevalent interests of states. To the contrary, if we assume that states have an interest in promoting the welfare of their residents, then recognizing the right to family unification immigration not only poses no threat, but actually serves its residents' interests. Since this logic applies with regard to the respective states of both one family member and the other seeking unification, there is no problem in both states recognizing a right to immigration for each case of family unification.

Problems with immigration for family reunification arise in states that fulfil the following conditions: (1) They realize the rights of specific nation(s) to selfdetermination; (2) they also include minority groups that are not entitled to selfdetermination rights within these states; and (3) the immigrants seeking family reunification belong to these groups and seek to join them. The interests of a state in this specific situation in protecting the rights of the groups entitled to selfdetermination within its territories could be threatened by immigration on the basis of family unification if a particularly large number of such immigrants enters and assimilates into minority groups that refuse to integrate themselves into the cultures of the groups entitled to self-determination in the given state.

The likelihood of immigrants arriving under family reunification in order to join integration-resistant minorities in numbers that would pose an immediate threat to the right of other groups to self-determination seems to be particularly uncommon. Therefore, the interest in family unification does seem to justify a right of entrance into 
such states. Moreover, even in cases in which immigration seeking family reunification threatens the interests of groups in cultural self-determination within a given state, the best way to minimize such a threat is not necessarily to abolish family unification rights to immigration. Instead, measures must be taken in order to encourage the integration of the immigrants into one of the cultures eligible for self-determination in the given state. And if these measures are insufficient, the number of those eligible for immigration for family reunification could be limited by imposing reasonable age restrictions and, ultimately, through the imposition of periodical quotas.

\section{RefugeE IMMIGRATION RightS}

For present purposes, refugees are all those who beg entrance into a state because their lives, liberty, or dignity are at great and immediate danger if they are not granted asylum. There is no doubt that these urgent interests justify a right to asylum. If a person's life or dignity is under imminent danger, it is difficult to imagine state interests strong enough to justify abstention from saving him/her. However, the important question in such a case is whether the right to asylum automatically implies the right to enter the immigration track, which would allow the asylum seeker to settle permanently in the country offering asylum. I believe that asylum seekers can only be prevented from permanent settlement in the event that the number of asylum seekers expected to strike roots in the country as a result of granting refugees a right to enter the immigration track threatens the state's control in serving its citizens' interests in public order, security, economic stability, or the preservation of cultural identity. The number beyond which permanent asylum seekers begin to pose a threat differs from state to state and would certainly be contested. Yet ultimately, irrespective of how to solve such disputes, it seems that at least as long as the number of refugees expected to enter a state and establish roots there does not endanger the state's ability to protect the aforementioned interests of its citizens, the right of refugees to be given the status of immigrants must be recognized. However, we must also acknowledge that although highly unlikely, there could be circumstances under which states may be justified in limiting these rights by specific quotas.

Acknowledging the possibility of imposing limitations on refugee and the admission of immigrants for family reunification may give rise to conceptual or normative doubts. It could be argued that if the number of prospective family unification immigrants or refugees deemed eligible is limited by quotas, then these people's right to immigrate is not based solely on their being immigrants seeking family reunification or refugees. Moreover, if the number of immigrants seeking family unification or refugees deemed 
eligible is limited by quotas, then what is the difference between the duty of states to periodically admit immigrant quotas on the basis of the interest people have in emigrating out of states discussed above and the obligation of states to accept quotas of family unification immigrants and refugees?

The answer is that in the case of immigrants seeking family reunification and refugees, the quota limitation may be imposed only beyond a certain number of individuals belonging to these groups who have chosen to activate their right to immigrate. Regular immigrants entering on quotas, on the other hand, are selected on a case-by-case basis, balancing various criteria. Immigrants belonging to this latter type are not identified by one general characteristic by virtue of which they have a right to immigrate. Limiting family unification and refugee immigrants by means of quotas is similar to the limitations applying in exceptional circumstance to the right to receive healthcare in emergency situations where the authorities are unable to provide it to all those who have been injured. All three are cases in which we are required to protect particularly critical interests of other specific individuals, interests worthy of our willingness to pay a significant price in terms of our own common interests.

Situations in which there is a very large number of refugees (in the context of which it could be justified to set quotas and thereby limit the right of refugees to immigrate into a state), or situations in which minority groups who are justly expected to integrate into the larger society and refuse to do so (and it may therefore be justified to set quotas limiting the rights of their family members to immigrate into the country in question), just like situations of mass injury, are exceptional and undesirable, and therefore should not guide our positions regarding rights. By their nature, rights follow from normative priorities and normative hierarchies under regular and not undesirable circumstances.

To conclude: I argue in this Article that states have two types of moral obligations in regards to immigrant intake. First, they are obliged to accept quotas of immigrants who have no individual rights to entrance prior to the determination of such quotas in one case or another. Second, they are obligated to admit immigrants who are individually entitled to enter, namely refugees and family unification immigrants. However, states could be justified under certain conditions to limit the entrance of refugees and family unification immigrants through various qualifications and even quotas.

The above complex thesis offers a middle ground between two positions supported by contemporary immigration theorists that I have rejected in the first parts of the Article: On the one hand, a position advocating a universal human right to immigration, and on the other, a position supporting a universal right of states to lock their gates to immigration. 